\title{
Article \\ Multi-Objective Path-Decision Model of Multimodal Transport Considering Uncertain Conditions and Carbon Emission Policies
}

\author{
Chao Zhu * (D) and Xiaoning Zhu
}

Citation: Zhu, C.; Zhu, X.

Multi-Objective Path-Decision Model of Multimodal Transport Considering Uncertain Conditions and Carbon

Emission Policies. Symmetry 2022, 14, 221. https://doi.org/10.3390/ sym 14020221

Academic Editors: José Carlos R. Alcantud and Jeng-Shyang Pan

Received: 30 October 2021

Accepted: 3 January 2022

Published: 24 January 2022

Publisher's Note: MDPI stays neutral with regard to jurisdictional claims in published maps and institutional affiliations.

Copyright: (C) 2022 by the authors. Licensee MDPI, Basel, Switzerland. This article is an open access article distributed under the terms and conditions of the Creative Commons Attribution (CC BY) license (https:// creativecommons.org/licenses/by/ $4.0 /)$.
School of Traffic and Transportation, Beijing Jiaotong University, Beijing 100044, China; xnzhu@bjtu.edu.cn

* Correspondence: 20114068@bjtu.edu.cn

\begin{abstract}
To develop low-carbon transport and promote sustainable economic development, this paper took the uncertainty in highway transport speed and transshipment time into account in the actual transport process and established multi-objective path-decision models of multimodal transport under different carbon policies. The expectation values of nonlinear uncertainties were estimated by Law of Large Numbers (LLN), and the models were solved by the K-shortest paths algorithm and non-dominated sorting algorithm (NSGA-II), whose advancement and effectiveness were verified through the comparison of SPEA2. Based on the Pareto theory, the optimally symmetrical compromise between the objectives and the influence of the transport speed uncertainty and carbon emission policies on path decisions were quantified and discussed. Taking the multimodal transport network of West Africa as the experimental background, the practicability of the path-decision results is analyzed, and a trade-off analysis is also conducted to provide the theoretical foundation for future freight transport planning.
\end{abstract}

Keywords: uncertainty; carbon emission policies; multimodal transport; multi-objective path-decision; NSGA-II; pareto theory; symmetrical compromise

\section{Introduction}

The fast pace of globalization and the development of international trade has spawned huge shipping demand, as more cargoes need to be transported; thus, the emissions produced during the transport process have inevitably increased, which makes the environment situation more serious [1]. Transport emission accounts for 39\% of global $\mathrm{CO}_{2}$ emission, which ranks first among electricity, industry, residential, commercial and other aspects [2]. The typical approaches to reduce the negative impact of logistic activities on the environment are implementing carbon-control policies and the transformation of existing freight transport modes [3]. Freight transport activities have taken up more than 30\% of carbon emissions and the fuel consumption of freight companies constitutes more than $40 \%$ of their total cost [1,2], which makes freight transport being one of the main emission sources. The adverse impact of carbon emissions released from shipping activities has restricted the development of transport industries.

Consequently, many national governments have introduced carbon emission policies, such as Carbon Tax, Carbon Cap and Cap-and-Trade [4]. The impact of various carbon policies on transport varies with the introduction of carbon taxes, which sets prices on emission directly, and which will urge shippers to choose more environmentally friendly transport modes; thus, the total cost of transport will not sharply increase [5,6]. Meanwhile, carbon tax policy is easy to implement though emission-level uncertainty remains [7]. The Carbon Cap policy, which is generally modeled by enforcing an upper bound on emission, underlines the necessity of cost-emission trade-offs to go in quest of the best transport way, such as switching to low-emitting technology and greener transport modes [8]. Similar to Carbon Cap, Cap-and-Trade can significantly decrease carbon emission by correctly setting 
limits [9]. A finite number of carbon credits are bought and sold in a market regulated by a third party. According to different carbon-control policies, decision makers can make different path decisions.

Multimodal transport is an economical way to transform existing freight transport modes, while in the meantime, multimodal transport under a carbon emission policy is uncommon [10]. The low efficiency of unimodal transport (highway) and its lack of combination with other modals (e.g., railway, waterway) makes it quite hard to lower the carbon emission from a holistic perspective, so its prolonged positive effects are difficult to exert. Multimodal transport means carrying cargoes through two or more transport modes, offering an efficient, reliable and sustainable service for freight transport. Compared with unimodal transport, multimodal transport can minimize its negative environmental impact by as much as $57 \%$ in terms of carbon emissions and is quite appealing to both research and shipping decision makers [11].

During the multimodal transport process, in order to follow the "green" concept, the belief of a carbon emissions reduction is investigated by route planning or transport network designing. In previous studies, planning models were built where carbon emissions are cited as evaluation indexes while not considered as the minimized objective. In multimodal transport problems, procedures and approaches for reducing carbon emissions are examined. For regulating policies, the effects are studied and evaluated to signify its importance in logistic activities [12,13]. However, few of these studies focused on the impact of policies on path-decision problems, especially in multimodal transport. Different implementations of carbon policies will affect the transport mode selection, thus exerting a more significant impact on the total cost or total volume of carbon emissions. Therefore, to uphold the "green" idea, it is necessary to study the multi-objective path-decision problem of multimodal transport under different carbon policies.

Uncertainty exists in transport process and is reflected in transport speed, transport time and transit time. Transport speed uncertainty is caused by the difference in road conditions. Transshipment time is affected by the stevedoring equipment, level and capacity of the different nodes. Under uncertain conditions, if it is modeled and solved according to the determined situation, the decision results are inconsistent with the actual transport scenarios [14]. Handling these uncertainties can help prompt a strategic, tactical and operational decision [15]. There is a gap between the actual transport situation handling and traditional uncertainty programming, such as stochastic programming [16], fuzzy programming [17], heuristic optimization [18] or scenario-based optimization [19], and it is logically impracticable to obtain the exact value of the uncertainty parameters [20]. Hence, in this paper, the mathematical expectation of the function corresponding to the uncertain variable is taken to deal with the problem.

In urban logistic activities, multimodal transport inevitably concerns highway transport, as enormous interference factors, such as the speed instability, will disrupt the normal operation of the overall transportation system. Highway transport as a major component of the multimodal transport process is the main contributor to the total carbon emissions, and there is a correlation between them. Studies suggest that the variation in speed will lead to the increase of carbon emissions and low transport efficiency. Average speed and multi-objective models are built to demonstrate the relationship and trade-off analysis between speed and carbon emissions [21-23]. In a nutshell, to achieve sustainable transport while retaining a high transport efficiency, it is obligatory to simultaneously consider the impacts of different carbon policies and highway transport speed on the path decision of the multimodal transport problem; therefore, here, a multi-objective approach is applied to reach the best symmetrical compromise between the goals.

Considering a single objective in the real problem is not practical for we cannot achieve one goal without jeopardizing other interests. Since we cannot optimize all the target values, the best way is to reach a symmetrical compromise [24]. Multi-objective optimization originated from three areas: economic equilibrium and welfare theories, game theory and pure mathematics. As an artificial intelligence approach, it can effectively 
address complicated problems. The general framework is to inspect a set of solutions, with which an acceptable level will be satisfied $[25,26]$. Nowadays, there has emerged two modern methods to solve multi-objective optimization problems: one is to integrate all the objective functions into one synthetical formulation or select one objective function as the major-optimized one while moving the others to the constraints. Utility theory, weighted sum method, etc., are applied while the best choice of the utility functions or weights is rather difficult to determine and quite arbitrary since it relies heavily on the decisionmaker's preference. A different combination of weights will greatly influence the calculated results. For the latter case, the constraint values need to be set for the objective functions, which is also quite difficult to measure. A promising method is to give a set of Pareto optimal solutions, which are not dominating each other. The Pareto optimal solution sets, of which the symmetrical compromise can be reached, are preferred by decision makers because they are more practical in dealing with real-life problems and allow them to do a trade-off analysis to proceed the thinking process more comprehensively; so, Pareto theory is the most widely adopted method to deal with multi-objective optimization problems.

A trade-off analysis is an effective measure to study the multi-objective path-decision problem. It is a process of cognizing the conflicting objectives to help decision makers assess the benefits and risks, based on which a symmetrical discussion can be implemented. For example, Yu et al. [27] and Duran et al. [28] conducted a trade-off analysis to reveal the interactive relationship of multiple objectives and demonstrated the benefits of considering certain decisions or elements to optimize a system configuration. In this paper, the trade-off analysis is adopted to evaluate how the carbon policies and highway transport speed affect the system performance and the symmetrical relationship among our proposed objectives [29].

Few studies have shown the impact of different carbon emission policies on route planning and there is a lack of quantitative analyses (the specific comparisons can be found in Table 1). This study aims to provide a heterogenous scheme in the context of multimodal transport. The contributions of this paper are as follows. First, the stochastic expected value model is used to describe the uncertainty in the transport and transshipment process. Through LLN and stochastic simulation, the uncertain conditions are linearized, which effectively reduces the complexity of the solution. Next, based on different carbon emission policies, a multi-objective path-decision model of multimodal transport is constructed in order to realize a symmetrical compromise between the economy and environmental impacts. Third, according to different transport scenarios, the Pareto frontiers with a number of non-dominated solutions are given. The influence of uncertain conditions and carbon emission policies on path decision making is quantified.

Table 1. Comparison with the most related studies.

\begin{tabular}{|c|c|c|c|c|c|c|c|c|c|c|c|}
\hline \multirow{2}{*}{ Article } & \multirow{2}{*}{$\begin{array}{l}\text { Transport } \\
\text { Time }\end{array}$} & \multirow{2}{*}{$\begin{array}{c}\text { Transport } \\
\text { Cost }\end{array}$} & \multirow{2}{*}{$\begin{array}{l}\text { Carbon } \\
\text { Emission }\end{array}$} & \multirow{2}{*}{$\begin{array}{l}\text { Uncertain } \\
\text { Conditions }\end{array}$} & \multicolumn{2}{|c|}{$\begin{array}{l}\text { Objective } \\
\text { Function }\end{array}$} & \multicolumn{2}{|c|}{$\begin{array}{c}\text { Scenario } \\
\text { Mode }\end{array}$} & \multicolumn{3}{|c|}{ Solving Method } \\
\hline & & & & & $\mathbf{M}^{1}$ & $\mathrm{~S}^{1}$ & $\mathbf{M}$ & $S$ & KSP & NSGA-II & Others \\
\hline [3] & & $\checkmark$ & 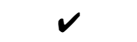 & $v$ & $\checkmark$ & & $v$ & & & & $v$ \\
\hline [17] & $\checkmark$ & $\checkmark$ & & $\checkmark$ & & $\checkmark$ & $v$ & & & & $\checkmark$ \\
\hline [20] & & $\checkmark$ & $\boldsymbol{V}$ & $\boldsymbol{V}$ & $\boldsymbol{v}$ & & & $\boldsymbol{v}$ & & & $\checkmark$ \\
\hline [30] & $\checkmark$ & $\checkmark$ & $\checkmark$ & & $\checkmark$ & & 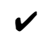 & & & & $\checkmark$ \\
\hline [31] & $\boldsymbol{V}$ & $v$ & & & & $v$ & & $\boldsymbol{v}$ & & & $\checkmark$ \\
\hline [32] & $\checkmark$ & $\checkmark$ & & & & $v$ & & $\checkmark$ & $\checkmark$ & & $\checkmark$ \\
\hline [33] & $\boldsymbol{V}$ & $v$ & & $\checkmark$ & $\boldsymbol{v}$ & & $\boldsymbol{v}$ & & & $\boldsymbol{V}$ & \\
\hline [34] & $\checkmark$ & $\checkmark$ & $\checkmark$ & & $v$ & & & $v$ & & & $v$ \\
\hline [35] & $\checkmark$ & $\checkmark$ & & & & $\checkmark$ & & $\checkmark$ & & & $\nu$ \\
\hline $\begin{array}{l}\text { This } \\
\text { study }\end{array}$ & $\nu$ & $\checkmark$ & $\checkmark$ & $\boldsymbol{\nu}$ & $\checkmark$ & & $\boldsymbol{v}$ & & $\checkmark$ & $\checkmark$ & $\checkmark$ \\
\hline
\end{tabular}

${ }^{1}$ M: Multi; S: Single.

The rest of the paper is organized as follows: Section 2 introduces the modelling methodology of the multi-objective path-decision problem. Section 3 provides solution 
methods to cope with the proposed models. Section 4 presents the case study of West Africa freight transport to analyze the impacts of different carbon policies on path decisions under highway transport uncertainty. Finally, the conclusions of this paper and the potential extensions from this research are discussed in Section 5.

\section{Modelling Methodology}

\subsection{Problem Description}

The potential uncertainties and causes in the actual multimodal transport process are shown in Figure 1. Enterprises deliver goods from the origin to the destination with combined transport. Due to the uncertain conditions during transportation, it is necessary to plan the route scheme under uncertainty, so as to make the goods meet the delivery time constraints and realize the optimal economic benefits. Furthermore, in order to evaluate the impact of a variation in the uncertain conditions during the transport process, to provide risk decision support to enterprises, this study establishes a multi-objective multimodal path-decision model of multimodal transport.

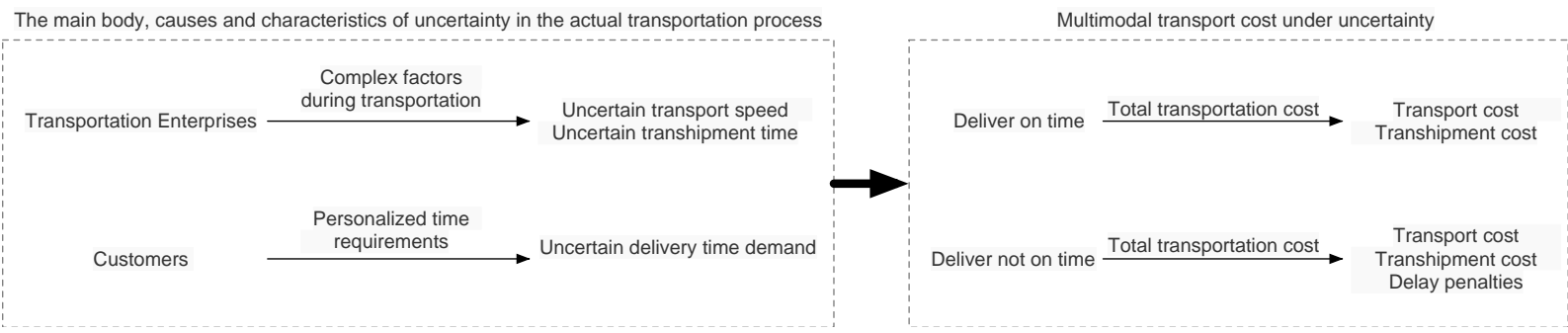

Figure 1. Study motivation and background.

\subsection{Assumptions}

- The path is acyclic, i.e., the same node or transport path can be passed at most once.

- The same batch of goods cannot be separated in the process of transport. For one transport mode, only one path between adjacent nodes can be used.

- In addition to the start and the end point, cargoes can be transferred at any node.

- The total quantity of goods is smaller than that of all paths and nodes.

\subsection{Parameters}

The notation of the parameters and variables is shown in Table 2.

\subsection{Model Establishment}

The uncertain conditions can be specifically formulated as the follows:

$$
\begin{gathered}
T_{1}=\sum_{(h, i) \in A} \sum_{k \in M_{(h, i)}} x_{(h, i)}^{k} \frac{S_{(h, i)}^{k}}{v_{(h, i)}^{k}} \\
T_{2}=\sum_{i \in N} \sum_{k \in M_{(h, i)}} \sum_{l \in M_{(i, j)}} y_{i}^{k, l} T_{i}^{k, l} \\
E\left(T_{0}\right)=E\left(T_{1}\right)+E\left(T_{2}\right)
\end{gathered}
$$

Equation (1) denotes the transport time $T_{1}$, which is concerned with the transport distance and speed. Equation (2) denotes the total transshipment time $T_{2}$, which is concerned with the unit transshipment time between adjacent nodes. Equation (3) formulates the expected total transport time $T_{0}$. 
Table 2. Subscripts and parameters used in the mathematical formulations.

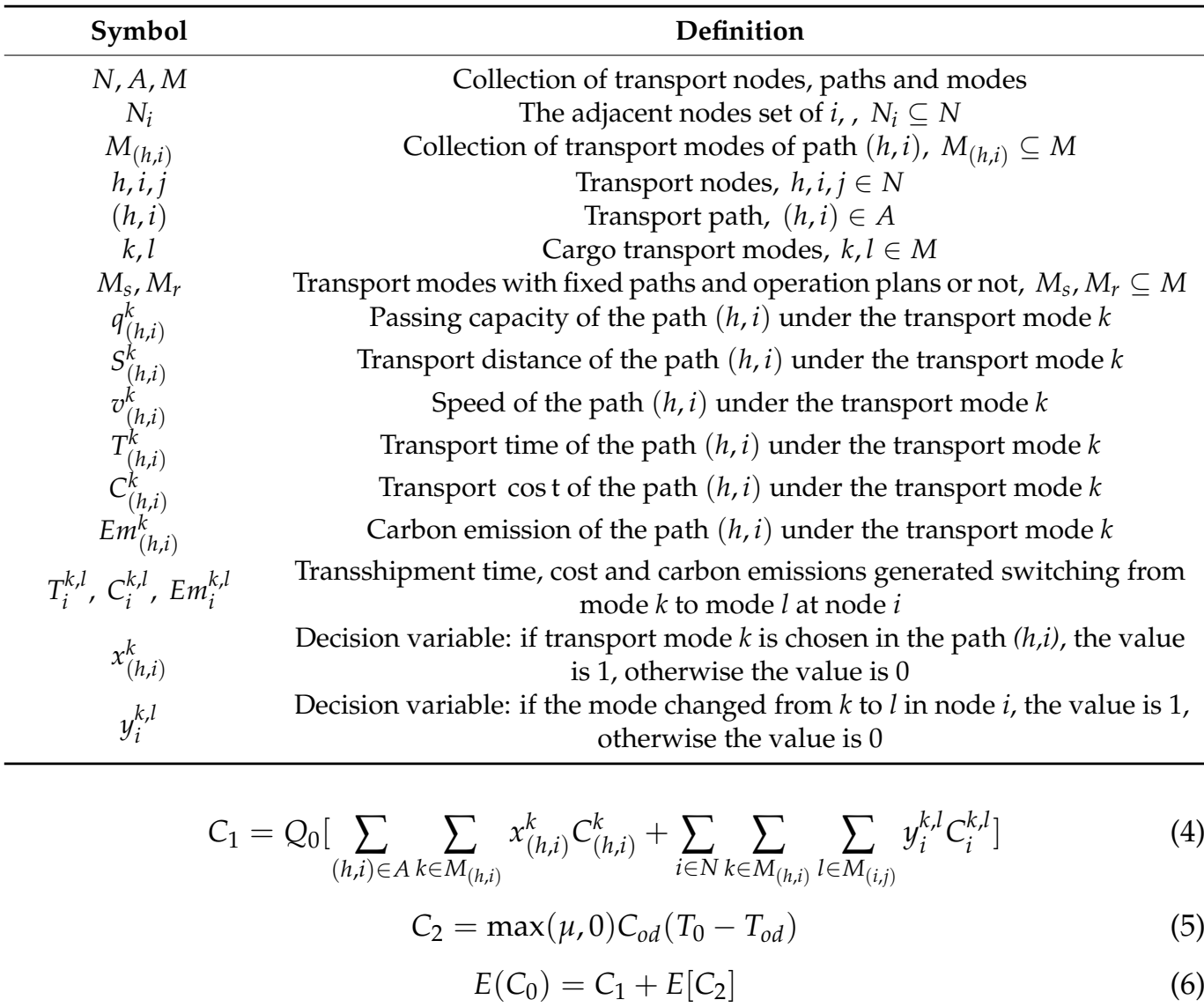

Equation (4) denotes the sum of transport and transshipment cost $C_{1}$, which is dependent on the total volume of cargoes $Q_{0}$. The penalty cost for delay is represented as Equation (5), where $C_{o d}$ is the unit delay penalty cost, and $T_{o d}$ is the prescribed arrival time, $\mu=\operatorname{sgn}(t)=\left\{\begin{array}{ll}-1 & T_{0}-T_{o d}<0 \\ 0 & T_{0}-T_{o d}=0 \\ 1 & T_{0}-T_{o d}>0\end{array} \quad\right.$. Equation (6) indicates the expected total cost $C_{0}$.

Under uncertain conditions, whether the goods will arrive on time is a random variable subject to a $0-1$ distribution. Define variable $h\left(\lambda_{r}\right), h\left(\lambda_{r}\right)=\left\{\begin{array}{ll}1 & T_{0}-T_{o d}<0 \\ 0 & \text { otherwise }\end{array}\right.$. The expectation of the punctuality of the cargoes' arrival can be expressed as follows:

$$
E\left[h\left(\lambda_{r}\right)\right]=P\left(T_{0}-T_{o d}<0\right) \geq \alpha
$$

In Equation (7), $\alpha$ is the expected threshold of the punctuality of the cargoes' arrival time, $\alpha \in(0,1)$.

The multimodal transport path-decision problem belongs to the NP hard problem. Therefore, Stochastic Simulation and LLN, which is able to transform the nonlinear content in the model and reduce the solving complexity, are explored here to estimate the expected value. $r$ groups of samples $\lambda_{r}=\left(v_{(h, i) r}^{k}, T_{i r}^{k, l}\right)$ are generated by Random Simulation, in which $1<r<R$.

$$
\begin{gathered}
\frac{1}{R}\left[\sum_{r=1}^{R} \sum_{(h, i) \in A} \sum_{k \in M_{(h, i)}} x_{(h, i)}^{k} \frac{S_{(h, i)}^{k}}{v_{(h, i)^{r}}^{k}}+\sum_{r=1}^{R} \sum_{i \in N} \sum_{k \in M_{(h, i)}} \sum_{l \in M_{(i, j)}} y_{i}^{k, l} T_{i r}^{k, l}\right] \rightarrow E\left[T_{1}\right]+E\left[T_{2}\right] \text {, a.s. } \\
\frac{\sum_{r=1}^{R} h\left(\lambda_{r}\right)}{R} \rightarrow E\left[h\left(\lambda_{r}\right)\right]=P\left(T_{0}-T_{o d}<0\right) \text {, a.s. }
\end{gathered}
$$


where $R \rightarrow \infty$. The left side of the arrows in Equations (8) and (9) are the estimated values of expectations of the total transport time and the punctuality of the cargoes' arrival. After the uncertain conditions are transformed, the optimization models under different carbon emission policies are shown as follows:

(1) Without a carbon emission policy

In this scenario, the model takes the minimization of the estimated values $T_{0}{ }^{\prime}$ and $C_{0}{ }^{\prime}$ as the objectives and the estimated value of the punctuality of the cargoes' arrival as the constraint, which is shown as Equation (10):

$$
\left\{\begin{array}{l}
\min T_{0}^{\prime}=\frac{1}{R}\left(\sum_{r=1}^{R} T_{1 r}+\sum_{r=1}^{R} T_{2 r}\right) \\
\min C_{0}{ }^{\prime}=C_{1}+\frac{1}{R} \sum_{r=1}^{R} C_{2 r} \\
\text { s.t. } \frac{1}{R} \sum_{r=1}^{R} h\left(\lambda_{r}\right) \geq \alpha
\end{array}\right.
$$

(2) Carbon Cap Policy

Carbon Cap policy requires that the sum of the transport carbon emissions $E m_{1}$ and transshipment carbon emissions $E m_{2}$ should be no more than the emission threshold proposed by regulatory authorities $E m_{u}$, which is illustrated as Equations (11) and (12):

$$
\begin{aligned}
E m_{1} & =\sum_{(h, i) \in A} \sum_{k \in M_{(h, i)}} x_{(h, i)}^{k} E m_{(h, i)}^{k} \\
E m_{2} & =\sum_{i \in N} \sum_{k \in M_{(h, i)}} \sum_{l \in M_{(i, j)}} y_{i}^{k, l} E m_{i}^{k, l}
\end{aligned}
$$

The calculation methods of carbon emissions for different transport modes are different. If $k \in M_{s}$, the volume of the generated carbon emission is only related to the transport distance, and $E m_{0}$ is a fixed value; if $k \in M_{r}$, the volume of carbon emissions is affected by uncertain conditions, then $E m_{0}$ is a non-fixed value. The objectives and constraints of the path-decision model under Carbon Cap policy is shown as Equation (13):

$$
\left\{\begin{array}{l}
\min T_{0}{ }^{\prime}=\frac{1}{R}\left(\sum_{r=1}^{R} T_{1 r}+\sum_{r=1}^{R} T_{2 r}\right) \\
\min C_{0}{ }^{\prime}=C_{1}+\frac{1}{R} \sum_{r=1}^{R} C_{2 r} \\
\text { s.t. } E m_{1}+E m_{2} \leq E m_{u} \\
\text { s.t. } \frac{1}{R} \sum_{r=1}^{R} h\left(\lambda_{r}\right) \geq \alpha
\end{array}\right.
$$

Specifically, if $k \in M_{r}$, then

$$
E m_{1}=\frac{1}{R} \sum_{r=1}^{R} E_{(h, i) r}^{k}
$$

(3) Carbon Tax Policy 
Under the Carbon Tax policy, the total carbon emissions generated in the transport process are charged with a carbon tax rate $E_{w}$, which is included in the total cost. Under this policy, the optimization objectives and constraints are as Equation (15):

$$
\left\{\begin{array}{l}
\min T_{0}^{\prime}=\frac{1}{R}\left(\sum_{r=1}^{R} T_{1 r}+\sum_{r=1}^{R} T_{2 r}\right) \\
\min C_{0}^{\prime}=C_{1}+\frac{1}{R} \sum_{r=1}^{R} C_{2 r}+E m_{0} E_{w} \\
\text { s.t. } \frac{1}{R} \sum_{r=1}^{R} h\left(\lambda_{r}\right) \geq \alpha
\end{array}\right.
$$

(4) Cap-and-Trade Policy

Under the Cap-and-Trade policy, enterprises have a fixed carbon emission quota $E m_{l}$. If there is any surplus, the remaining quota can be sold at a certain price $E_{s}$, and the profit will offset part of the transport cost. If the quota has been overdrawn, certain quota $E_{b}$ should be traded, and the purchase expenditure will be included in the total transport cost. The optimization objectives and constraints of the model are shown as Equation (16) under the Cap-and-Trade policy:

$$
\left\{\begin{array}{l}
\min T_{0}^{\prime}=\frac{1}{R}\left(\sum_{r=1}^{R} T_{1 r}+\sum_{r=1}^{R} T_{2 r}\right) \\
\min C_{0}^{\prime}=C_{1}+\frac{1}{R} \sum_{r=1}^{R} C_{2 r}+\delta\left(E m_{0}-E m_{l}\right) \\
\text { s.t. } \frac{1}{R} \sum_{r=1}^{R} h\left(\lambda_{r}\right) \geq \alpha
\end{array}\right.
$$

following constraints:

In Equation (16), $\delta=\left\{\begin{array}{ll}E_{S} & E_{m_{0}}-E_{m_{1}}<0 \\ E_{b} & \text { otherwise }\end{array}\right.$. The above models are subject to the

$$
\begin{gathered}
\sum_{h \in N_{i}} \sum_{k \in M_{(h, i)}} x_{(h, i)}^{k}-\sum_{j \in N_{i}} \sum_{l \in M_{(i, j)}} x_{(i, j)}^{l}=\left\{\begin{array}{l}
1, i=d \\
0, i \neq 0, i \neq d ; \forall i \in N \\
-1, i=0
\end{array}\right. \\
\sum_{k \in M_{(h, i)}} x_{(h, i)}^{k} \leq 1 \forall(h, i) \in A \\
0 \leq \sum_{k \in M_{(h, i)}} \sum_{l \in M_{(i, j)}} y_{i}^{k, l} \leq 1 \forall i \in N, k \neq l \\
Q_{0} x_{(h, i)}^{k} \leq q_{(h, i)}^{k} \forall k \in M_{(h, i)} \\
Q_{0} y_{i}^{k, l} \leq q_{i} \forall k \in M_{(h, i)}, l \in M_{(i, j)}, k \neq l \\
k=l \forall l \in\{O, D\}, \forall k \in M_{(h, i)}, \forall l \in M_{(i, j)} \\
x_{(h, i)}^{k}, y_{i}^{k, l} \in\{0,1\} \forall h, i \in N, k \in M_{(h, i)}, l \in M_{(i, j)}
\end{gathered}
$$

Constraint (17) represents the conservation constraint of cargo flow between adjacent transport paths; Constraint (18) indicates that only one transport mode can be adopted in one path for the same good; Constraint (19) denotes that cargoes can be transferred at most once on one node; Constraint (20) ensures that the quantity of cargoes on any path is less than or equal to the service capacity of this path; Constraint (21) ensures that the cargo quantity on any transport node is no more than its service capacity; Constraint (22) means that no transshipment of cargoes will occur at the origin or destination nodes; and Constraint (23) means that the value of the decision variable should be 0 or 1 . 


\section{Solution Methods}

The path-decision problem investigated in this paper is a multi-objective problem. As most of the multi-objective problems (such as vehicle routing problem, traveling salesman problem, scheduling problem, etc.) have to realize several objectives, instead of considering a unilateral objective, multi-objective optimization addresses the problem from a holistic perspective. As for multi-objective path-decision problems, approaches to solving them can be divided into exact and heuristic algorithms. In terms of the heuristic algorithm, uncertain conditions will inevitably bring about nonlinear path-decision contents, which reduces the solving efficiency and is easy to fall into the local optimum. For this reason, this paper applies the exact and heuristic algorithm, i.e., the Path Search Algorithm, to search for feasible paths.

The NSGA-II algorithm is one of the most commonly used multi-objective optimization algorithms. This method ensures the diversity of the solutions by using the concept of crowding distance while considering the Elite principle and the non-dominated sorting. The diversity of solutions maintained is the main advantage of the NSGA-II algorithm. Therefore, the NSGA-II algorithm was applied to obtain the non-dominated solution set of the path scheme. The general framework of the methodology is shown in Figure 2.

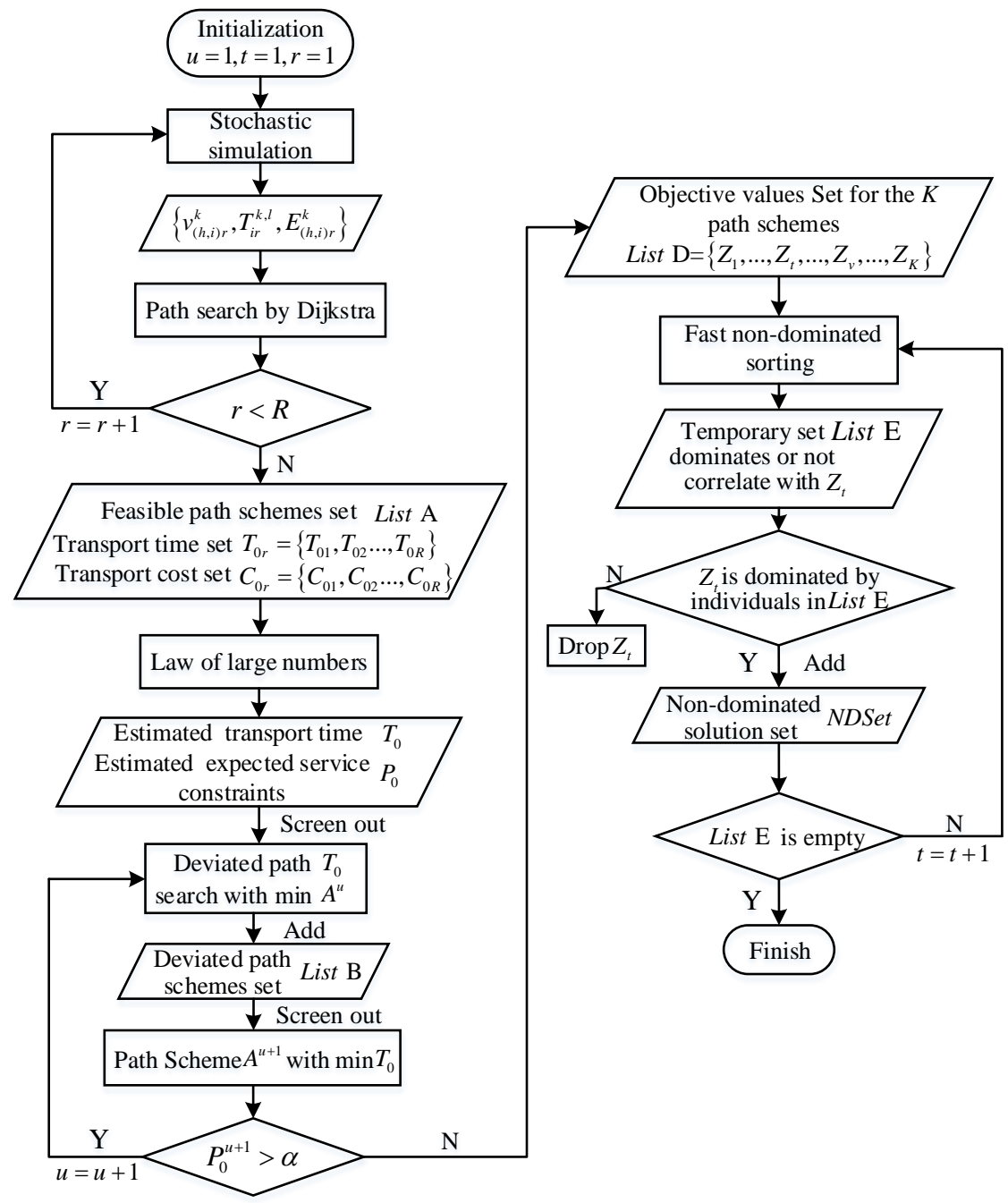

Figure 2. Framework of methodology.

\subsection{Path Search Algorithm}

In view of the existence of the expected arrival punctuality constraints, the Dijkstra Path Search Algorithm is unable to effectively screen the path schemes that meet the constraints. Therefore, we applied the K-shortest paths algorithm to search for the deviated 
path schemes, then sorting and screening for feasible path schemes. Compared with the original path schemes, the deviated ones have the same starting point, ending point and several public nodes, but deviate from the original path on some nodes [22]. The path search method is as follows:

Initialize set List $\mathrm{A}$, List $\mathrm{B}$, List $\mathrm{C}$ and List $\mathrm{D}$. Set the sum of transport time $T_{(h, i)}^{k}$ and transit time $T_{i}^{k, l}$ as the edge weight, $P_{0}=h\left(\lambda_{r}\right)$ as the expected arrival punctuality of each path scheme, $r$ as the random simulation times, $r=1,2, \ldots, R$; and $u$ as the number of iterations, $u=1,2, \ldots, K$.

Step 1. Simulate randomly $r$ groups of uncertain variable values $\left\{v_{(h, i)}^{k}, T_{i r}^{k, l}, E_{(h, i) r}^{k}\right\}$ according to the settings. Collect basic data such as unit freight charge and carbon emission per unit transport, and establish a path matrix.

Step 2. Solve matrix by the Dijkstra algorithm. Search the feasible paths in the multimodal transport network and output $T_{0 r}, C_{0 r}, h\left(\lambda_{r}\right)$.

Step 3. Place $R$ groups of the uncertain variable values into the path matrix and iterate the Dijkstra algorithm repeatedly until $r=R$. Output the total transport time $T_{0 r}=\left\{T_{01}, T_{02} \ldots, T_{0 R}\right\}$ and cost $C_{0 r}=\left\{C_{01}, C_{02} \ldots, C_{0 R}\right\}$ corresponding to the random simulation value.

Step 4 . Add the values in the output array and proceed LLN estimation by dividing the result through $R$. Add the feasible route schemes and its corresponding estimated total transport time $T_{0}$ and expected arrival punctuality $P_{0}$ to List $\mathrm{A}$;

Step 5. Search for the path scheme $A^{u}$ with the shortest $T_{0}$ and its corresponding $T_{0}^{u}$ and $P_{0}^{u}$ in List A. Search for the deviated path schemes of $A^{u}$ and add them to List B.

Step 6. Search for the path scheme $A^{u+1}$ with the shortest $T_{0}$ either and its corresponding $T_{0}^{u+1}$ and $P_{0}^{u+1}$ in List B.

Step 7. Repeat iterative Step 5 and Step 6 until $P_{0}^{K+1}<\alpha$. Output the top $K$ path schemes that meet the expected arrival punctuality constraint. Store the path scheme in List $\mathrm{C}$ and its corresponding $T_{0}$ and $C_{0}$ in List $\mathrm{D}$.

\subsection{Path Scheme Non-Dominated Sorting}

Non-domination is defined as follows: $Z_{t}=\left(T_{0 t}, C_{0 t}\right)$ and $Z_{v}=\left(T_{0 v}, C_{0 v}\right)$ are two individuals in the objective functions $\min T_{0}$ and $\min C_{0}$. When two sub-objectives $C_{0 t}$ and $T_{0 t}$ in $Z_{t}$ are not greater than that in $Z_{v}$, and at least one sub-objective value is less than the target value in $Z_{v}$, it is called that $Z_{t}$ dominates $Z_{v}$, and vice versa. If $Z_{t}$ is not dominated by other individuals, it is a non-dominated solution. If there is no dominant relationship between individuals $Z_{t}$ and $Z_{v}$, there is no correlation between individuals. Generally speaking, the Pareto front is the set of the non-dominated solutions whose number is greater than one in two-dimensional space. For any solution in the Pareto front, it is usually not dominated by other solutions outside or within the front. Moreover, the contradiction gap between the target values is the smallest, which provides a wide range of choices. Therefore, through the trade-off characteristics between target values, we can further reach a symmetrical compromise of all the non-dominated solutions in the Pareto front and obtain the optimal solutions. The non-dominated sorting method is as follows:

Set List $\mathrm{D}=\left\{Z_{1}, \ldots, Z_{t}, \ldots, Z_{v}, \ldots, Z_{K}\right\}, 1<t, v<K, Z_{t}=\left(T_{0 t}, C_{0 t}\right)$ is an individual in List D. NDSet is non-dominated solution set which is initialized null.

Step 1. Search forward $(k--)$ from the last individual $Z_{K}$ to find the first individual $Z_{v}$ which dominates $Z_{1}$ or is irrelevant to $Z_{1}$. Exchange the position of $Z_{v}$ and $Z_{1}$.

Step 2. Search backward (1++) from the first individual $Z_{v}$ to find the first individual $Z_{t}$ which dominates $Z_{1}$. Exchange the position of $Z_{v}$ and $Z_{1}$.

Step 3. Repeat Steps 1 and 2 until the individuals are all sorted. At this time, the individuals on $Z_{1}$ 's left dominate $Z_{1}$ or are irrelevant to $Z_{1}$ and are stored in the temporary set List $E$. The individuals on $Z_{1}{ }^{\prime} s$ right, which are dominated by $Z_{1}$, are discarded. If there is no individual on the left that can dominate $Z_{1}$, it will be stored in the non-dominated solution set; if there existing at least one, the individual will be discarded. At this time, the first comparison process is completed. 
Step 4. Repeat the comparison process in Step 3 until the temporary set List E with dominated and irrelevant individuals is null. At this point, all non-dominated solutions have been stored in N D Set.

\subsection{Trade-Off Analysis on Non-Dominated Path Schemes}

The non-dominated solutions concerning the transport time and cost of NDSet constitutes the Pareto front in two-dimensional space, as shown by the curve in Figure 3. Among them, the 1\# Pareto front has the highest rank, and the solution in this front is the optimal non-dominant solution. The 2\# Pareto front is the suboptimal Pareto front, and the solution in this front is only dominated by the solution in the 1\# Pareto front. Influenced by uncertain conditions and carbon emission policies, the Pareto front may shift from the $2 \#$ front to $1 \#$ front, which is called the Pareto improvement [23]. A study on the non-dominated scheme and its improvement in the Pareto front has been helpful to quantify the influence degree of the uncertainty conditions and to conduct a trade-off analysis concerning the symmetrical compromise [24].

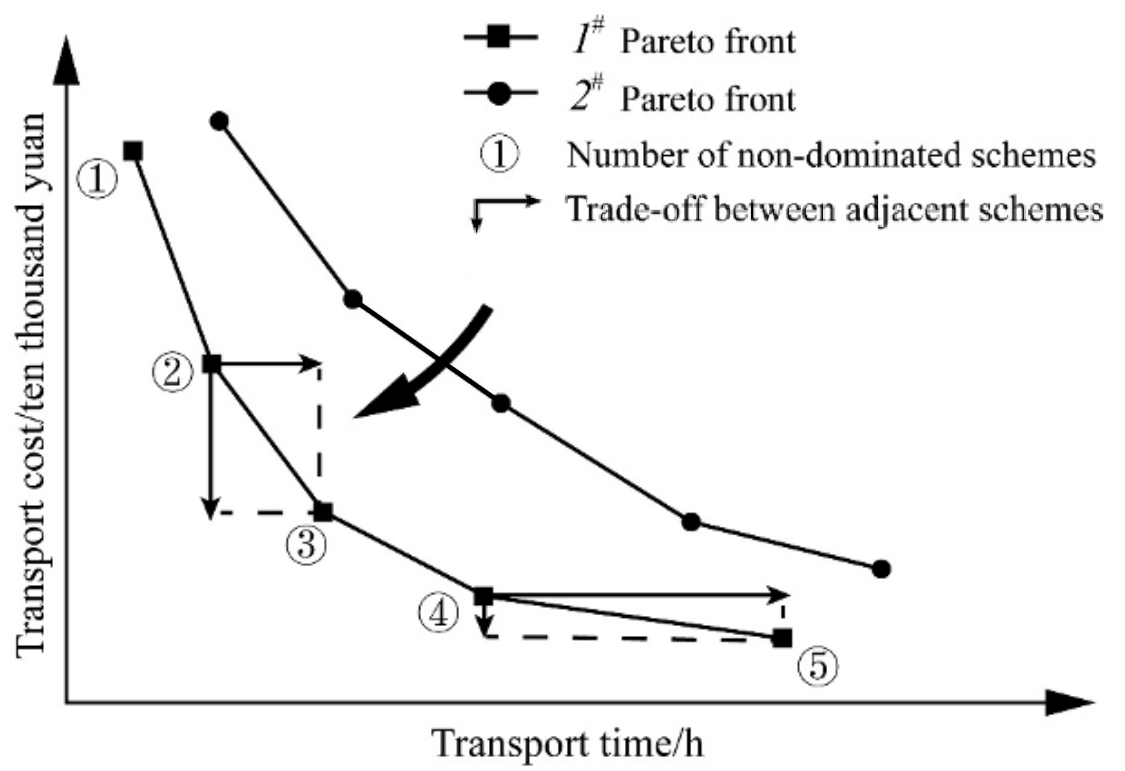

Figure 3. Schematic diagram of the Pareto front.

\section{Implementation and Analysis}

\subsection{Study Site Selection and Description}

This paper takes the multimodal transport network of West Africa as the research background to further verify the effectiveness of the proposed models and algorithm. This shipment plan is to deliver a batch of phosphate ore weighing 10TEU from Agadez, Niger, West Africa, to Freetown Port, which can be transported by trucks, trains and ships. The study site is shown in Figure 4.

The speed of the railway and waterway is assumed the certain values. The speed is no higher than $60 \mathrm{~km} / \mathrm{h}$ of railway and $27 \mathrm{~km} / \mathrm{h}$ of waterway in West Africa [25,26]. Influenced by the uncertain conditions, the highway transport speed is an uncertain value subject to a normal distribution. The capacity of the roads in West Africa is about $500 \mathrm{pcu} / \mathrm{h} / \mathrm{ln}[27,28]$; the BPR function (Equation (24)) was used to represent the highway transport speed. Five groups of transport scenarios were set, from congestion to unimpeded situations, which are shown in Table 3.

$$
v_{i}=\frac{v_{i 0}}{\left[1+\alpha\left(\frac{Q}{C}\right)^{\beta}\right]}
$$




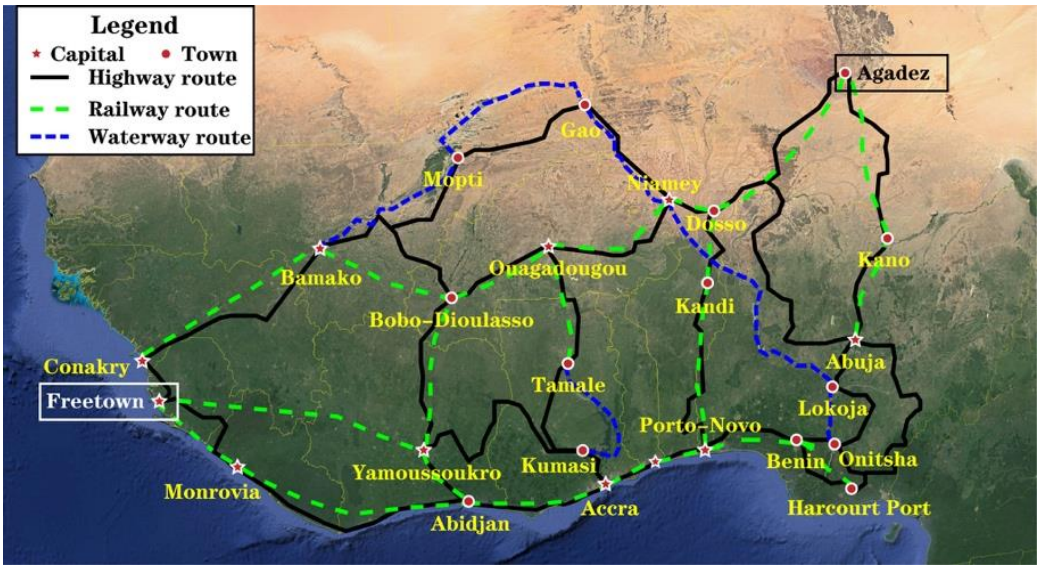

Figure 4. Multimodal transport network of West Africa.

Table 3. Uncertain highway transport scenarios.

\begin{tabular}{cccc}
\hline Transport Scenario & Speed $(\mathbf{k m} / \mathbf{h})$ & $\begin{array}{c}\text { Value of BPR } \\
\text { Function }(\mathbf{p c u} / \mathbf{h} / \mathbf{l n})\end{array}$ & Characteristic \\
\hline 1 & $\mathrm{~N}(90,3)$ & 459 & Unimpeded \\
2 & $\mathrm{~N}(70,3)$ & 650 & Normal traffic flow \\
3 & $\mathrm{~N}(55,5)$ & 890 & General traffic flow \\
4 & $\mathrm{~N}(40,5)$ & 955 & Large traffic flow \\
5 & $\mathrm{~N}(25,5)$ & 1057 & Congestion \\
\hline
\end{tabular}

In Equation (24), $v_{i}$ denotes the highway speed and $v_{i 0}$ is the free-flow speed. $Q$ is the actual traffic volume $(\mathrm{pcu} / \mathrm{h} / \mathrm{ln})$, and $C$ is the road capacity $(\mathrm{pcu} / \mathrm{h} / \mathrm{ln}) ; \alpha=0.15, \beta=4$.

During multimodal transport, the setting of an uncertain transshipment time is shown in Table 4. The transshipment time and the waiting time of the next transport stage, respectively, conform to a normal distribution and uniform distribution. Equation (25) is the probability density function of the normal distribution.

Table 4. Characteristics and distribution interval of the uncertain transshipment time.

\begin{tabular}{cccc}
\hline \multicolumn{2}{c}{ Transshipment Time (h) } & \multicolumn{2}{c}{ Waiting Time of the Next Stage (h) } \\
\hline $\begin{array}{c}\text { Transshipment } \\
\text { Mode }\end{array}$ & Transshipment Time & Characteristic & Waiting Time \\
\hline $\mathrm{H} \rightarrow \mathrm{R}$ & $\mathrm{N}(7,1)$ & Unimpeded & $\mathrm{U}(2,0.5)$ \\
$\mathrm{H} \rightarrow \mathrm{W}$ & $\mathrm{N}(8,1)$ & General & $(2,5)$ \\
$\mathrm{R} \rightarrow \mathrm{W}$ & $\mathrm{N}(4,0.5)$ & Congestion & $\mathrm{N}(5,1)$ \\
\hline
\end{tabular}

${ }^{1}$ H: Highway; R: Railway; W: Waterway.

If the probability density function of the random variable $x$ can be expressed as

$$
f(x)=\frac{1}{\sigma \sqrt{2 \pi}} e^{-\frac{1}{2}\left(\frac{x-\mu}{\sigma}\right)^{2}}
$$

Then, $\mathrm{x}$ conforms to the normal distribution, represented as $x \sim N(\mu, \sigma)$, where $x \in(-\infty,+\infty)$.

The unit prices of freight transport and transshipment between two modes were determined by West Africa's fluctuating standard [36], and delay penalty only occurs when the total transport time is greater than $80 \mathrm{~h}$. The carbon emissions, which is expressed as Equation (26), are related to transport distance and total cargo volume. 


$$
E_{(h, i)}^{k}=\left[\varepsilon_{0}+\varepsilon_{1} \cdot v_{(h, i)}^{k}+\varepsilon_{2} \cdot\left(v_{(h, i)}^{k}\right)^{2}+\varepsilon_{3}\left(v_{(h, i)}^{k}\right)^{3}+\frac{\varepsilon_{4}}{v_{(h, i)}^{k}}+\frac{\varepsilon_{5}}{\left(v_{(h, i)}^{k}\right)^{2}}+\frac{\varepsilon_{6}}{\left(v_{(h, i)}^{k}\right)^{3}}\right] \cdot\left\lceil\frac{Q_{0}}{H^{k}}\right\rceil \cdot 10^{-3}
$$

In Equation (26), $\left\{\varepsilon_{0}, \varepsilon_{1}, \varepsilon_{2}, \varepsilon_{3}, \varepsilon_{4}, \varepsilon_{5}, \varepsilon_{6}\right\}$ are the correlation coefficients, where the values of the coefficients are $\{1576,-17.6,0,0.00117,0,36067,0\} ; H^{k}$ is the loads of the freight trucks. The units carbon emission of the other transport modes is shown in Table 5.

Table 5. Per unit carbon emission of freight transport and the transshipment of railways and waterways.

\begin{tabular}{cccc}
\hline Transport Mode & $\begin{array}{c}\text { Carbon Emission } \\
\mathbf{( k g / k m )}\end{array}$ & Mode Switching & $\begin{array}{c}\text { Transshipment Carbon } \\
\text { Emission (kg/TEU) }\end{array}$ \\
\hline Railway & 0.156 & $\mathrm{H} \rightarrow \mathrm{R}$ & 2.17 \\
Waterway & 0.644 & $\mathrm{H} \rightarrow \mathrm{W}$ & 1.98 \\
& $\mathrm{R} \rightarrow \mathrm{W}$ & 1.92 \\
\hline
\end{tabular}

In the early stage of the development of low-carbon transport in West Africa, the carbon tax rate is set at 10 yuan/tonCO2e; the market price of the carbon emission quota may fluctuate due to the stability of the trading environment.

\subsection{Results and Discussions}

This section analyzes the influence of an uncertain transport environment and different carbon emission policies on path decision; the Pareto fronts obtained under the five scenarios are shown in Figure 5.

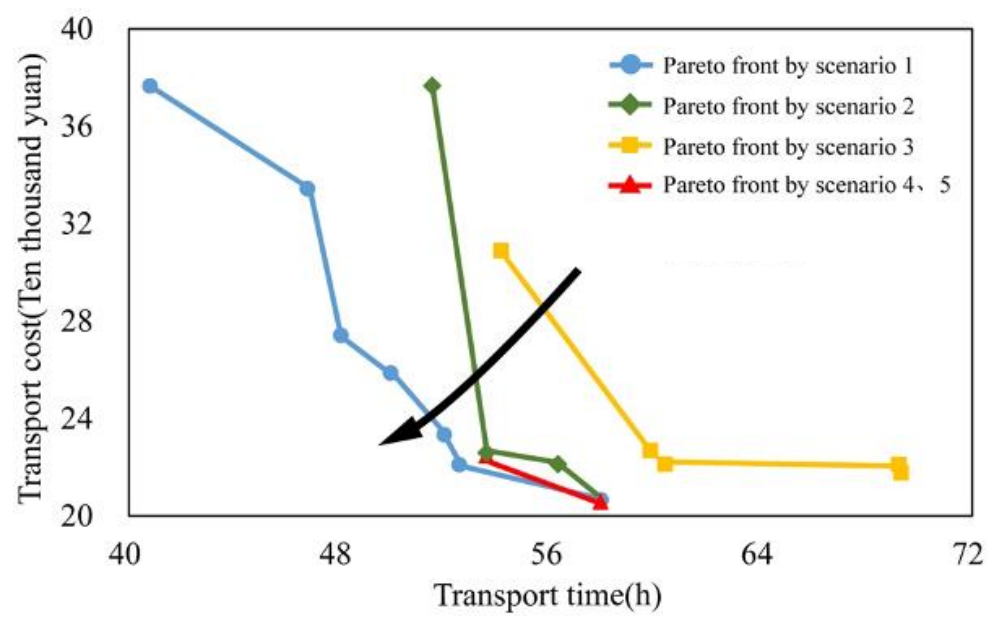

Figure 5. Pareto fronts obtained under each scenario.

\subsubsection{Under Uncertain Transport Conditions}

It can be seen that as the highway transport conditions deteriorate, the Pareto front moves from the high level to the low level, and the path schemes in the front are also reduced. When the transport condition becomes worse until congested, the Pareto front level is upgraded again. At this time, the path schemes in the front all adopts whole-journey railway transport.

Under the different transport scenarios, the non-dominated path-decision schemes are occupied by rail-road combined transport, and then the railway transport gradually takes advantage with the deterioration of highway transport conditions. At this time, the carbon emissions also decreased. It can also be found that all the non-dominated path-decision schemes do not include waterway transport. The reasons are that (1) waterway transport in West Africa is fragmented, i.e., it cannot form the water-water continuous transport 
process. Costs spent on mode shift also make waterway transport lose its advantage in profits; and (2) preference will be given to other modes if the transport time is no different.

When the carbon emission policies are not implemented, the worse the highway conditions are, the more path schemes adopt low-carbon transport. After conducting carbon emission policies, the nature and ability of uncertain conditions in influencing the decision making in a path scheme will be discussed in the following section.

\subsubsection{Under Different Carbon Emission Policies}

(1) Carbon Cap Policy

The implementation of Carbon Cap policy can only influence path schemes whose carbon emissions exceed the threshold in the non-dominated solution set. Moreover, with the deterioration of highway transport conditions, railway transport gradually takes advantage, and the restriction ability of this policy will be weakened as well.

(2) Carbon Tax Policy

When a low tax rate of 10 yuan/tonCO2e is adopted, the carbon tax does not exceed $0.1 \%$ of the total transport cost and is negligible. At this stage, the implementation of this policy has little influence on the path decision. By referring to the experience of developed countries such as Sweden, the carbon tax rate is increased to 250, 500 and 1000 yuan / tonCO2e separately to study the impact of a high tax rate on the results of path decision making.

As shown in Figure 6, in Scenario 1, when the tax rate is raised to 500, a new route scheme that adopted whole-journey railway transport, whose carbon emission is the lowest, is added in the Pareto front and its low carbon emission gives this scheme an advantage in the total transport cost. Moreover, it is notable that under the tax rate of 500 and 1000, the path-decision result is the same.

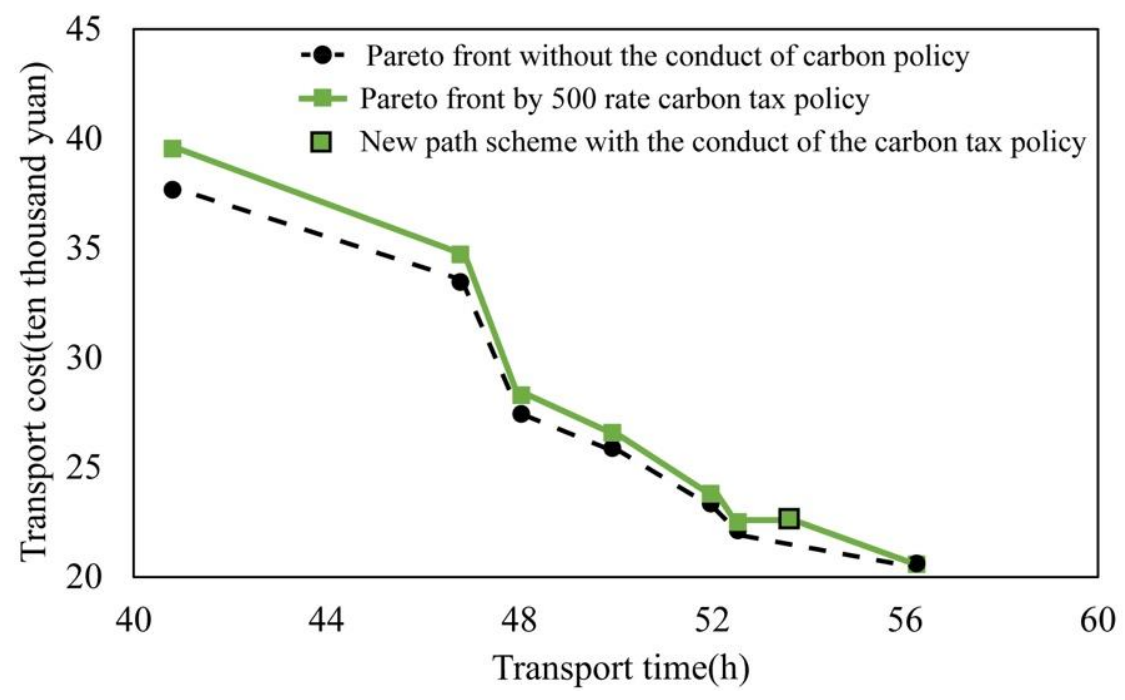

Figure 6. Influence of carbon tax rate on path decision in Scenario 1.

However, as shown in Figure 7a,b, in Scenarios 2 and 3, only when the tax rate reaches 1000 can it affect the path-decision result. Among them, (1) Scenario 2 deletes one path scheme that adopts rail-road combined transport; (2) the new path schemes in Scenario 3 is exactly the same as that of Scenario 1; and (3) all the path schemes in Scenarios 4 and 5 adopt whole-journey rail transport, so they are not affected by the Carbon Tax policy. 


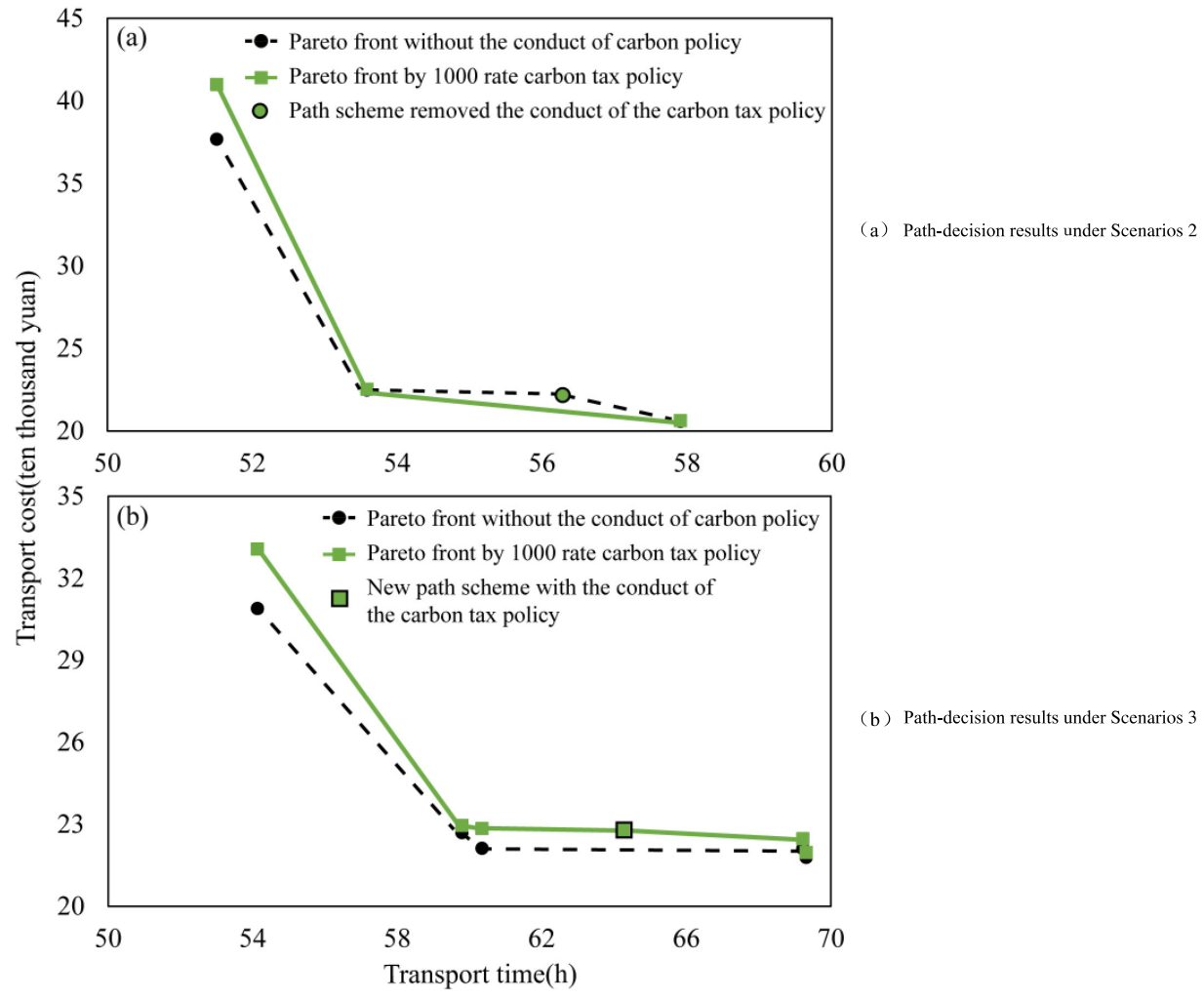

Figure 7. Influence of carbon tax rate on the path-decision results in Scenarios 2 and 3 (respectively shown in subfigures $\mathbf{a}, \mathbf{b})$.

It can be seen that with the implementation of carbon tax policy, the increase of transport cost weakens the level of the Pareto front. For the management department, not only can it improve the carrier's awareness of low-carbon transport, but also increase the tax revenue. However, only if the carbon tax rate reaches high enough will it affect the multimodal path decision. Moreover, as the highway transport conditions become worse, the carbon tax rate needs to be continuously increased so that it will again affect the path decision results. However, it should be stressed that imposing high taxes in West Africa will hurt the enthusiasm of transport companies and put more freight pressure on low-carbon transport modes such as railway and waterway.

(3) Cap-and-Trade Policy

Under the Cap-and-Trade policy, the trading in the carbon emission quota belongs to the free market. According to commodity supply and demand, the trading market is divided into buyer's, seller's and equal trading markets. The buyer's market is dominated by customers, and the price of the carbon quota is lower than the conventional market price, while the seller's market is the opposite. Carrier enterprises can trade the carbon emission quota according to their freight transport plan. Assume the carbon emission quota as 15 tons and take 500 yuan and 1000 yuan/tonCO2e as the market price, respectively, to conduct the analysis.

In Scenario 1, when the market price is 500 yuan/tCO2e, the Cap-and-Trade policy improves the results of path-decision schemes. Specifically, as shown in Figure 8, (1) in the seller's market, the improvement direction and the path schemes of the Pareto front change distinctively; and (2) the Pareto front of the buyer's market is basically overlapped with that of the equal trading market, which lie between the Pareto front of the seller's market and the Pareto front of the implementation of carbon tax policy. 


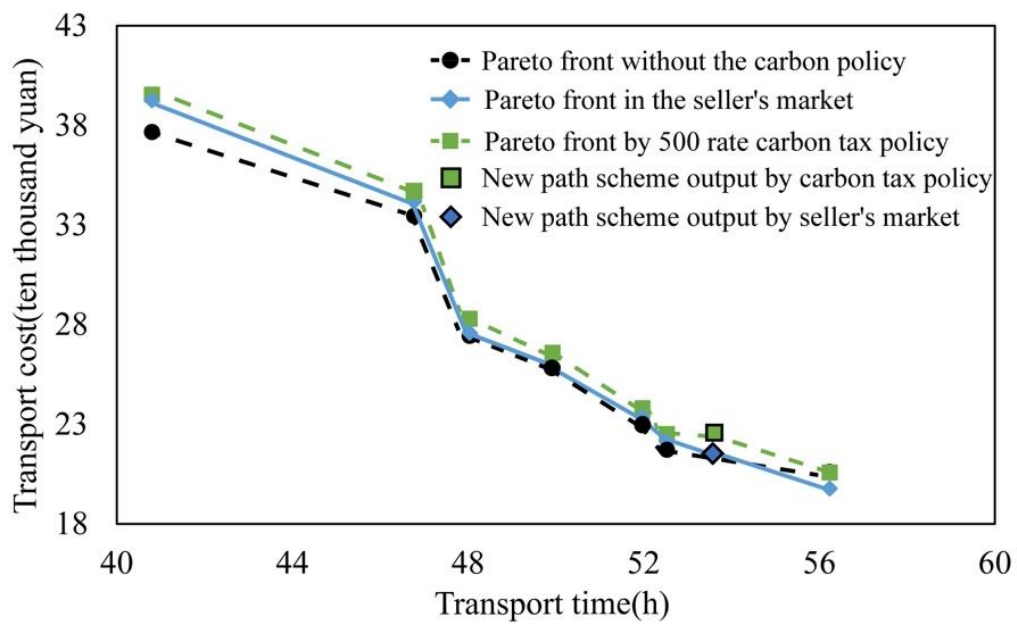

Figure 8. Influence of the implementation of the Cap-and-Trade policy under a seller's market on path decisions in Scenario 1.

In Scenarios 2 and 3, when the market price is 1000 yuan/tCO2e, the obtained set of non-dominated path schemes is shown in Figure 9a,b. In this scenario, the impact of the Cap-and-Trade policy on the results of path decision is similar to that of the Carbon Tax policy. However, it can be found that the path schemes of Scenarios 4 and 5 are mainly based on railway transport, whose carbon emissions are lower. Therefore, no matter what market pricing is adopted, the obtained path schemes remain unchanged.

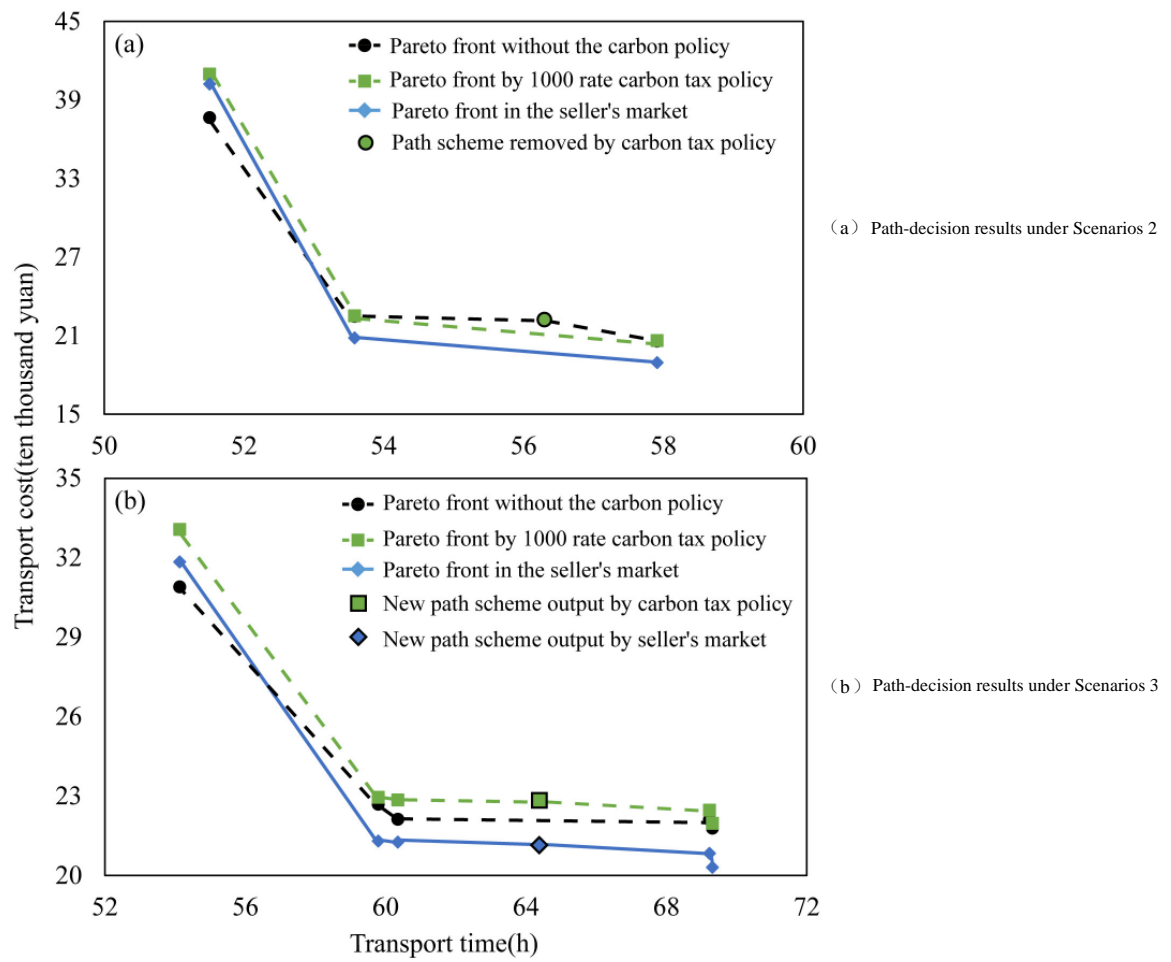

Figure 9. Influence of the implementation of a Cap-and-Trade policy under a seller's market on path decisions in Scenarios 2 and 3 (respectively shown in subfigures $\mathbf{a}, \mathbf{b}$ ).

Combined with the above results, and compared with the non-dominated path schemes without a carbon emission policy, the influence degrees of the different carbon emission policies on the path-decision results are shown in Table 6. 
Table 6. Influence degrees of different carbon policies implementation on path-decision results.

\begin{tabular}{|c|c|c|c|c|c|}
\hline \multirow[b]{2}{*}{$\begin{array}{l}\text { Carbon } \\
\text { Emission } \\
\text { Policy }\end{array}$} & \multicolumn{2}{|c|}{ Theoretical Research } & \multicolumn{3}{|c|}{ Application in Real Life } \\
\hline & $\begin{array}{c}\text { Improvement } \\
\text { Direction of } \\
\text { Pareto Front }\end{array}$ & $\begin{array}{c}\text { Path Schemes in Pareto } \\
\text { Front }\end{array}$ & $\begin{array}{c}\text { Reduce } \\
\text { Transport Time }\end{array}$ & $\begin{array}{c}\text { Reduce } \\
\text { Transport Cost }\end{array}$ & $\begin{array}{l}\text { Reduce Carbon } \\
\text { Emissions }\end{array}$ \\
\hline $\begin{array}{l}\text { Carbon Cap } \\
\text { Policy }\end{array}$ & Insignificant & Add or drop schemes & No & Yes & Yes \\
\hline $\begin{array}{l}\text { Carbon Tax } \\
\text { Policy }\end{array}$ & Improved $^{1}$ & $\begin{array}{l}\text { Improve the scheme and } \\
\text { change its objective values }\end{array}$ & No & No & Yes \\
\hline $\begin{array}{l}\text { Cap-and-Trade } \\
\text { Policy }\end{array}$ & Improved $^{1}$ & $\begin{array}{l}\text { Improve the scheme and } \\
\text { change its objective values }\end{array}$ & No & Yes & Yes \\
\hline
\end{tabular}

${ }^{1}$ Compared with the Pareto front without carbon emission policies.

Under uncertain transport scenarios, the implementation of a Carbon Cap policy can greatly reduce carbon emissions compared with the other two policies. The Carbon Cap policy is a hard constraint, which directly eliminate the schemes of exceeding the carbon emission threshold and can largely save transport cost. However, this policy is unfriendly to transport enterprises and not conducive to the development of the logistics industry in West Africa under the current socio-economic background. The other two policies are to awake the carrier's awareness of environmental protection through taxation and carbon trade, so that the carrier can choose the transport scheme with fewer carbon emissions freely, which can be viewed as the soft constraints. In general, under the seller's market, the implementation of a Cap-and-Trade policy exerts the most distinctive positive impact on the path decision, which comprehensively coordinate the nexus among social, economic and environmental benefits and endow transport enterprises with great autonomy.

\subsection{Algorithm Performance Comparison}

In order to solve the multi-objective optimization problem proposed in this paper, this paper applies an exact algorithm, and combines the path search algorithm with the fast non-dominated sorting algorithm to obtain the Pareto frontier. The K-shortest algorithm was used to search, sort and screen the feasible path schemes, and the fast non-dominated sorting algorithm was employed to output the Pareto frontier. The relevant data of a West Africa multimodal transport network was used to compare the results of NSGA-II with that of zitzler, Laumann and Thiele's SPEA2 algorithm [37].

At present, many indicators have been adopted to evaluate the performance of solving algorithms, such as CPU time [38], the number of Pareto optimal solutions [39], error rate [40] and so on. In this paper, CPU time is used to highlight the solving efficiency of the algorithm. We used MATLAB 2016a on an Intel Core i5-11320h CPU (2.7 GHz). The CPU results are shown in Table 7.

Table 7. CPU time comparison of the two algorithms.

\begin{tabular}{cccc}
\hline & Carbon Cap Policy & Carbon Tax Policy & Cap-and-Trade Policy \\
\hline NSGA-II & $265 \mathrm{~s}$ & $284 \mathrm{~s}$ & $254 \mathrm{~s}$ \\
SPEA2 & $310 \mathrm{~s}$ & $345 \mathrm{~s}$ & $324 \mathrm{~s}$ \\
\hline
\end{tabular}

Therefore, the algorithm proposed in this paper can obtain the solution of the model in a shorter time.

\section{Conclusions}

In this paper, the multi-objective path-decision problems under different carbon emission policies are studied considering the highway transport uncertainty. As a way to achieve sustainable transport, the implementation of a low-carbon policy has proven to exert a positive role in reducing carbon emissions. However, the transport of goods is affected 
by multiple factors, where uncertain road transport conditions have a great impact on the transport cost and time. The Path Search Algorithm and Fast NSGA-II were adopted to obtain the set of feasible paths and non-dominated solution sets of path schemes. Through the case study of West Africa freight transport, the effectiveness of the proposed model and algorithms was verified, trade-off analysis and symmetrical discussion are also formulated.

The analysis of path schemes in non-dominant solutions shows that (1) improvement of the Pareto set was positively correlated to the changes in highway speed; (2) path schemes with carbon emissions exceeding the limit would be excluded under the implementation of a Carbon Cap policy; (3) only when the carbon tax rate was high enough could it influence the results of the path decision, and the implementation of a Carbon Tax policy would significantly drive up the transport cost; and (4) the implementation of a Cap-and-Trade policy had a positive impact on the path decision, and this influence would become more striking under a seller's market. The implementations of carbon emission policies are conductive to encouraging transport enterprises to project low-carbon transport plans and authorities to formulate relevant policies. However, for west African countries, their transport demand is not able to support the establishment of a carbon-trading market, and the implementation of a Carbon Tax policy might be hard given the economic situation in West Africa; therefore, it is more suitable to implement Carbon Cap and Carbon Tax policies. By analyzing the impact of different carbon emission policies and uncertain road conditions on transportation routes, this paper could help the local governments to reasonably adopt their carbon emission policies and form a stable market order in combination with the current situation of the local economy and transportation infrastructures.

Nevertheless, the study has its limitations. Based on different carbon emission policies, this paper considers the uncertainty of road transportation speed and cargo transshipment time in the multimodal transport process. However, factors such as the local market situation and market competition will also induce uncertainty in transport demand, as well as affect delivery efficiency and path decisions. In addition, the path-decision schemes in this paper were not specifically quantitatively investigated, while the final transport scheme still needs to be determined. Promising extensions stemming from this paper are as follows: (1) deeply consider the uncertain factors in the multimodal transport process and expand the Pareto theory to more complex conditions; (2) evaluate the advantages and disadvantages of the solution schemes in the Pareto set, and select the most feasible and practical transport scheme; and (3) assess how to transform a multi-objective path-decision problem into a single-objective optimization issue to search for the global optimum.

Author Contributions: Methodology, C.Z.; data curation, C.Z.; investigation, C.Z.; resources, X.Z.; writing-original draft preparation, X.Z.; writing-review and editing, C.Z. All authors have read and agreed to the published version of the manuscript.

Funding: This work is sponsored in part by the National Natural Science Foundation of China (U2034208), in part by the key project of science and technology research and development plan of China State Railway Group (grant number N2020X008).

Institutional Review Board Statement: Not applicable.

Informed Consent Statement: Not applicable.

Data Availability Statement: Not applicable.

Acknowledgments: This work is sponsored in part by the National Natural Science Foundation of China (U2034208), in part by the key project of science and technology research and development plan of China State Railway Group (grant number N2020X008). We also thank the anonymous referees and editor-in-chief.

Conflicts of Interest: The authors declare no conflict of interest. 


\section{References}

1. Asghari, M.; Al-e-hashem, S.M.J.M. Green vehicle routing problem: A state-of-the-art review. Int. J. Prod. Econ. 2021, $231,107899$. [CrossRef]

2. Palmer, P.I.; O’Doherty, S.; Allen, G.; Bower, K.; Bösch, H.; Chipperfield, M.P.; Connors, S.; Dhomse, S.; Feng, L.; Finch, D.P.; et al A measurement-based verification framework for UK greenhouse gas emissions: An overview of the Greenhouse gAs Uk and Global Emissions (GAUGE) project. Atmos. Chem. Phys. 2018, 18, 11753-11777. [CrossRef]

3. Jiang, J.; Zhang, D.; Meng, Q.; Liu, Y. Regional multimodal logistics network design considering demand uncertainty and $\mathrm{CO}_{2}$ emission reduction target: A system-optimization approach. J. Clean. Prod. 2020, 248, 119304. [CrossRef]

4. Zhou, X.; Wei, X.; Lin, J.; Tian, X.; Lev, B.; Wang, S. Supply chain management under carbon taxes: A review and bibliometric analysis-ScienceDirect. Omega 2021, 98, 102295. [CrossRef]

5. Zakeri, A.; Dehghanian, F.; Fahimnia, B.; Sarkis, J. Carbon pricing versus emissions trading: A supply chain planning perspective. Int. J. Prod. Econ. 2015, 164, 197-205. [CrossRef]

6. Fahimnia, B.; Sarkis, J.; Choudhary, A.; Eshragh, A. Tactical supply chain planning under a carbon tax policy scheme: A case study. Int. J. Prod. Econ. 2015, 164, 206-215. [CrossRef]

7. Almutairi, H.; Elhedhli, S. Modeling, analysis, and evaluation of a carbon tax policy based on the emission factor. Comput. Ind. Eng. 2014, 77, 88-102. [CrossRef]

8. Al-E-Hashem, S.M.; Baboli, A.; Sazvar, Z. A stochastic aggregate production planning model in a green supply chain: Considering flexible lead times, nonlinear purchase and shortage cost functions. Eur. J. Oper. Res. 2013, 230, 26-41. [CrossRef]

9. Abdallah, T.; Diabat, A.; Simchi-Levi, D. A carbon sensitive supply chain network problem with green procurement. In Proceedings of the 40th International Conference on Computers \& Indutrial Engineering, Awaji, Japan, 25-28 July 2010; pp. 1-6. [CrossRef]

10. Waltho, C.; Elhedhli, S.; Gzara, F. Green supply chain network design: A review focused on policy adoption and emission quantification. Int. J. Prod. Econ. 2019, 208, 305-318. [CrossRef]

11. Craig, A.J.; Blanco, E.E.; Sheffi, Y. Estimating the $\mathrm{CO}_{2}$ intensity of intermodal freight transportation. Transp. Res. Part D Transp. Environ. 2013, 22, 49-53. [CrossRef]

12. Fareeduddin, M.; Hassan, A.; Syed, M.; Selim, S. The Impact of Carbon Policies on Closed-loop Supply Chain Network Design Procedia CIRP 2015, 26, 335-340. [CrossRef]

13. Choudhary, A.; Sarkar, S.; Settur, S.; Tiwari, M. A carbon market sensitive optimization model for integrated forward-reverse logistics. Int. J. Prod. Econ. 2015, 164, 433-444. [CrossRef]

14. Bozorgi-Amiri, A.; Khorsi, M. A dynamic multi-objective location-routing model for relief logistic planning under uncertainty on demand, travel time, and cost parameters. Int. J. Adv. Manuf. Technol. 2016, 85, 1633-1648. [CrossRef]

15. Bozorgi-Amiri, A.; Jabalameli, M.S.; Al-E-Hashem, S.M.J.M. A multi-objective robust stochastic programming model for disaster relief logistics under uncertainty. OR Spectr. 2013, 35, 905-933. [CrossRef]

16. Malik, A.I.; Sarkar, B. Coordinating Supply-Chain Management under Stochastic Fuzzy Environment and Lead-Time Reduction. Mathematics 2019, 7, 480. [CrossRef]

17. Lu, Y.; Lang, M.; Sun, Y.; Li, S. A Fuzzy Intercontinental Road-Rail Multimodal Routing Model with Time and Train Capacity Uncertainty and Fuzzy Programming Approaches. IEEE Access 2020, 8, 27532-27548. [CrossRef]

18. Homayouni, Z.; Pishvaee, M.S.; Jahani, H.; Ivanov, D. A robust-heuristic optimization approach to a green supply chain design with consideration of assorted vehicle types and carbon policies under uncertainty. Ann. Oper. Res. 2021, 1-41. [CrossRef]

19. Gao, X.; Cao, C. A novel multi-objective scenario-based optimization model for sustainable reverse logistics supply chain network redesign considering facility reconstruction. J. Clean. Prod. 2020, 270, 122405. [CrossRef]

20. Ziaei, Z.; Jabbarzadeh, A. A multi-objective robust optimization approach for green location-routing planning of multi-modal transportation systems under uncertainty. J. Clean. Prod. 2021, 291, 125293. [CrossRef]

21. Sun, D.; Zhang, Y.; Xue, R.; Zhang, Y. Modeling carbon emissions from urban traffic system using mobile monitoring. Sci. Total Environ. 2017, 599-600, 944-951. [CrossRef]

22. Franceschetti, A.; Honhon, D.; Van Woensel, T.; Bektaş, T.; Laporte, G. The time-dependent pollution-routing problem. Transp. Res. Part B Methodol. 2013, 56, 265-293. [CrossRef]

23. Figliozzi, M. The impacts of congestion on time-definitive urban freight distribution networks $\mathrm{CO}_{2}$ emission levels: Results from a case study in Portland, Oregon. Transp. Res. Part C Emerg. Technol. 2011, 19, 766-778. [CrossRef]

24. Marler, R.; Arora, J. Survey of multi-objective optimization methods for engineering. Struct. Multidiscip. Optim. 2004, 26, 369-395. [CrossRef]

25. Mnif, M.; Bouamama, S. Firework Algorithm for Multi-Objective Optimization of A Multimodal Transportation Network Problem. Procedia Comput. Sci. 2017, 112, 1670-1682. [CrossRef]

26. Konak, A.; Coit, D.W.; Smith, A.E. Multi-objective optimization using genetic algorithms: A tutorial. Reliab. Eng. Syst. Saf. 2006, 91, 992-1007. [CrossRef]

27. Yu, B.; Gu, X.; Ni, F.; Guo, R. Multi-objective optimization for asphalt pavement maintenance plans at project level: Integrating performance, cost and environment. Transp. Res. Part D Transp. Environ. 2015, 41, 64-74. [CrossRef]

28. Duran-Micco, J.; Vermeir, E.; Vansteenwegen, P. Considering emissions in the transit network design and frequency setting problem with a heterogeneous fleet. Eur. J. Oper. Res. 2020, 282, 580-592. [CrossRef] 
29. Bai, Q.; Ahmed, A.; Li, Z.; Labi, S. A Hybrid Pareto Frontier Generation Method for Trade-Off Analysis in Transportation Asset Management. Comput. Civ. Infrastruct. Eng. 2014, 30, 163-180. [CrossRef]

30. Wang, Q.Z.; Chen, J.M.; Tseng, M.L.; Luan, H.M.; Ali, M.H. Modelling green multimodal transport route performance with witness simulation software. J. Clean. Prod. 2020, 248, 119245. [CrossRef]

31. Xu, W.; Rong, M. Research on Optimization of Expressway Logistics Path Based on the Advantages of Multimodal Transport in the Environment of Internet of Things. Wirel. Pers. Commun. 2021, 1-17. [CrossRef]

32. Luo, Y.; Zhang, Y.; Huang, J.; Yang, H. Multi-route planning of multimodal transportation for oversize and heavyweight cargo based on reconstruction. Comput. Oper. Res. 2021, 128, 105172. [CrossRef]

33. Yong, P.; Yong, P.; Luo, Y. The route problem of multimodal transportation with timetable under uncertainty: Multi-objective robust optimization model and heuristic approach. RAIRO-Oper. Res. 2021, 55, S3035-S3050.

34. Wang, Z.-Z.; Gu, M.-X.; Li, Q.-X.; Chu, R.-J. Multimodal Transportation Routing Optimization Considering Carbon Emissions in Uncertain Environment. In Proceedings of the 20th COTA International Conference of Transportation Professionals, Xi'an, China, 14-16 August 2020; pp. 5130-5142. [CrossRef]

35. Ge, D. Optimal path selection of multimodal transport based on Ant Colony Algorithm. J. Phys. Conf. Ser. 2021, $2083,032011$. [CrossRef]

36. Hickman, J.; Hassel, D.; Joumard, R.; Samaras, Z.; Sorenson, S. Methodology for Calculating Transport Emissions and Energy Consumption; The National Academies of Sciences, Engineering, and Medicine: Washington, DC, USA, 1999.

37. Zitzler, E.; Laumanns, M.; Thiele, L. SPEA2: Improving the Strength Pareto Evolutionary Algorithm; TIK-report; Eidgenössische Technische Hochschule Zürich (ETH): Zürich, Switzerland, 2001; Volume 103.

38. Khanduzi, R.; Peyghami, M.R.; Sangaiah, A.K. Data envelopment analysis and interdiction median problem with fortification for enabling IoT technologies to relieve potential attacks. Future Gener. Comput. Syst. 2018, 79, 928-940. [CrossRef]

39. Alikar, N.; Mousavi, S.M.; Ghazilla, R.; Tavana, M.; Olugu, E.U. Application of the NSGA-II algorithm to a multi-period inventory-redundancy allocation problem in a series-parallel system. Reliab. Eng. Syst. Saf. 2017, 160, 1-10. [CrossRef]

40. Habib, M.; Yalaoui, F.; Chehade, H.; Jarkass, I.; Chebbo, N. Multi-objective design optimisation of repairable k-out-of-n subsystems in series with redundant dependency. Int. J. Prod. Res. 2017, 55, 7000-7021. [CrossRef] 